\title{
BREVE CONTEXTUALIZAÇÃO DA ATUAL CONFIGURAÇÃO DA DEPENDÊNCIA LATINO-AMERICANA E A ECONOMIA MUNDIAL CAPITALISTA: UMA AGENDA DE DEBATES
}

\author{
José Raimundo Barreto Trindade ${ }^{1}$
}

RESUMO: A Teoria da Dependência (TD) surgiu em meados da década de 1960, em parte como uma reação ao aparente fracasso da análise e das propostas dos desenvolvimentistas e em grande medida como tentativa de explicar as novas características do desenvolvimento socioeconômico da região. Os teóricos da dependência argumentavam que a estratégia de industrialização baseada na substituição das importações era incapaz de produzir efeitos de ruptura com o subdesenvolvimento, pois o mesmo seria antes de tudo uma consequência e parte do processo de expansão mundial do capitalismo. $O$ artigo tem como objetivo central retomar a teoria da dependência enquanto aporte teórico robusto que colabora na interpretação contemporânea das sociedades latino-americanas e se propõe a estabelecer pontos de uma agenda de pesquisa centrada na atualidade e atualização deste aporte teórico. Inicialmente abordam-se os elementos históricos e categoriais sobre e da teoria da dependência; posteriormente, trata da relação entre a teoria da dependência marxista e sua interpretação do contexto latino-americano, buscando compreender as condições de manutenção e renovação da dependência latino-americana; por fim, propomos uma agenda de pesquisas e trabalhos, o que se mostra tanto profícuo, quanto necessário na presente conjuntura de instabilidade e de retrocessos sociais manifestos no Brasil e na América Latina.

Palavras-chave: Dependência. Teoria da Dependência. América latina.

ABSTRACT: The Theory of Dependency (TD) emerged in the mid-1960s, in part as a reaction to the apparent failure of developmentalists' analysis and proposals and to a large extent as an attempt to explain the new characteristics of socioeconomic development in the region. Dependency theorists argued that the industrialization strategy based on import substitution was incapable of producing disruptive effects on underdevelopment, since it would be primarily a consequence and part of the process of world expansion of capitalism. The main objective of this article is to retake dependence theory as a robust theoretical contribution that contributes to the contemporary interpretation of Latin American societies and proposes to establish points of a research agenda centered on the actuality and updating of this theoretical contribution. Initially, we approach the historical and categorical elements about and dependence theory; later, it deals with the relation between the theory of the dependence Marxist and its interpretation of the Latin American context, trying to understand the conditions of maintenance and renovation of the Latin American dependence; Finally, we propose an agenda of researches and works, which is both profitable and necessary in the present conjuncture of instability and manifest social setbacks in Brazil and Latin America.

Keywords: Dependency. Theory of Dependency. Latin America.

\footnotetext{
1 Professor Associado 3, vinculado ao PPGE/UFPA. Universidade Federal do Pará. E-mail: jrtrindade@uol.com.br
} 


\section{INTRODUÇÃO}

Nas últimas duas décadas a teoria da dependência foi retomada enquanto aporte de análise radical das formações latino-americanas. Esta tradição teórica tem uma longa história integrada tanto à interpretação econômica quanto sociológica continental.

A retomada deste aporte teórico se relaciona a nosso ver a cinco aspectos fortes: primeiramente o esgotamento dos modelos econômicos e sociais desenvolvimentistas e estimuladores de bases de maior complexidade industrial; segundo, e muito relacionado ao primeiro, às condições internacionais e, especialmente, a dinâmica econômica estadunidense se alterou profundamente, com movimentos oscilante e de profunda crise nas últimas décadas; terceiro, a revolução científico-técnica entra numa nova fase, com a imposição de uma quarta revolução industrial; quarto, desde os anos 1990 há um predomínio de segmentos rentistas no controle do sistema mundo capitalista e; quinto, porém de maior importância, a emergência da China enquanto potência regional, com fortes tendências a se impor enquanto potência beligerante global, o que refaz parcialmente a geopolítica da economia mundo capitalista e estabelece novos arranjos de disputa e interação, como por exemplo os Brics (grupo formado por Brasil, Rússia, Índia, China e África do Sul, alcançou sua maior expressão internacional em 2010).

Estes fatores não serão analisados aqui em detalhes, mas nos dão elementos de fundo para as proposições estabelecidas e a agenda de pesquisas propostas neste artigo. $O$ texto tem como objetivo central retomar a teoria da dependência enquanto aporte teórico robusto que colabora na interpretação contemporânea das sociedades latino-americanas e se propõe a estabelecer pontos de uma agenda de pesquisa centrada na atualidade e atualização deste aporte teórico. Dividimos o artigo em três seções: a primeira seção estabelece elementos históricos e categoriais sobre e da teoria da dependência; a segunda seção, trata da relação entre a teoria da dependência marxista e sua interpretação do contexto latinoamericano; a terceira seção busca atualizar a compreensão entre a dinâmica atual da economia capitalista mundial e as condições de manutenção e renovação da dependência latino-americana; por fim, propomos uma agenda de pesquisa e 
trabalhos, o que se mostra tanto profícuo, quanto necessário na presente conjuntura de instabilidade e de retrocessos sociais manifestos no Brasil e na América Latina.

\section{O APORTE DA DEPENDÊNCIA E AS CONDIÇÕES DE DESENVOLVIMENTO DESIGUAL NA AMÉRICA LATINA}

A Teoria da Dependência (TD) surgiu em meados da década de $1960^{2}$, em parte como uma reação ao aparente fracasso da análise e das propostas dos desenvolvimentistas e em grande medida como tentativa de explicar as novas características do desenvolvimento socioeconômico da região. Os teóricos da dependência argumentavam que a estratégia de industrialização baseada na substituição das importações era incapaz de produzir efeitos de ruptura com o subdesenvolvimento, pois o mesmo seria antes de tudo uma consequência e parte do processo de expansão mundial do capitalismo (Dos SANTOS 1970; 2015; GILPIN, 2002; KAY, 1989).

A relação de interdependência entre ou vários países e o sistema capitalista mundial torna-se uma relação de dependência a partir do momento em que algumas nações podem expandir-se por conta própria, enquanto outras, estando numa situação de dependência, só o podem fazê-lo limitadamente, em parte como reflexo da expansão dos países centrais (ALMEIDA FILHO, 2005).

Em termos teóricos, a TD constitui uma tentativa de entender a reprodução do sistema capitalista na periferia, enquanto um modo de produção que cria e amplia diferenciações em termos políticos, econômicos e sociais entre países e regiões, a partir do processo de desenvolvimento desigual e combinado. Esta teoria aparece, portanto, como uma crítica à tradicional visão do subdesenvolvimento como uma ausência de desenvolvimento ou teoria da modernização, que argumentava que o atraso dos países subdesenvolvidos era explicado pelos obstáculos que neles existiam a seu pleno desenvolvimento ou modernização (Dos Santos, 2000; AMARAL, 2012) ${ }^{3}$.

\footnotetext{
${ }^{2}$ As chamadas teorias da dependência são formuladas entre os anos de 1964 e 1973, e mantém sua influência até fins dos 1970, quando se consolida no meio acadêmico latino-americano, com o apoio dos Estados Unidos, a liderança do pensamento liberal-conservador do processo de redemocratização da América Latina (MARTINS, 2011).

${ }^{3}$ As teses de convergência estão principalmente vinculadas a chamada teoria da modernização de Rostow, segundo o qual o caminho para o desenvolvimento era universal, seguindo sucessivas fases. Como observa Martins (2011, p. 224) "a pretensão formulada pela teoria da modernização de um mesmo caminho de desenvolvimento para as diversas sociedades nacionais revela-se absurda". Entretanto o "etapismo" de Rostow terá profunda influência sobre o pensamento econômico latino-
} 
Diferente do desenvolvimentismo, a TD não condiciona subdesenvolvimento e desenvolvimento como etapas de um processo evolutivo, e sim como realidades que, ainda que estruturalmente vinculadas, são distintas e contrapostas, e por isso se fez necessário superar a compreensão de subdesenvolvimento enquanto uma situação de desenvolvimento pré-industrial. Dito isso, o subdesenvolvimento passa a ser compreendido como produto do desenvolvimento capitalista mundial, sendo por este motivo, uma forma específica de capitalismo (DUARTE \& GRACIOLLI, 2007).

Pode-se, em termos gerais, seguindo Blomstrom e Hettne (1990), resumir as ideias centrais defendidas pela TD em quatro pontos específicos:

i) o primeiro seria que a visão de subdesenvolvimento está intimamente ligada com a expansão dos países industrializados, o que implica a percepção de que subdesenvolvimento e desenvolvimento não são formas contraditórias e sim complementares;

ii) o segundo refere-se a dialética da totalidade capitalista: desenvolvimento e subdesenvolvimento são aspectos distintos do mesmo processo universal;

iii) o terceiro refere-se ao fato de que o subdesenvolvimento não pode ser considerado como um ponto de partida de um processo "evolucionista", ou seja, subdesenvolvimento gera mais subdesenvolvimento;

iv) o fato de a dependência não ser somente fenômeno externo, mas também e principalmente, uma condição da dinâmica e da estrutura interna de cada formação econômica nacional;

v) deve-se complementar com o significativo fator do grau de soberania dos Estados nacionais (OSÓRIO, 2012). A soberania refere-se à capacidade de execução e afirmação de políticas sociais, econômicas e bélicas por parte de cada Estado enquanto agente de poder autônomo. Assim as formações socioeconômicas dependentes apresentam grau de soberania restringida em algum dos aspectos centrais, seja na definição de políticas sociais, macroeconômicas, inclusive gestão do seu padrão monetário, e mesmo autonomia bélica.

Estes pontos justificam a ideia de que a produção capitalista é permanentemente desigual e excludente, e por conta disso possui características que reproduzem, ao mesmo tempo e na mesma medida, desenvolvimento e subdesenvolvimento em distintas regiões. Vale acrescer que a dependência se

americano e, principalmente, sobre as ações "desenvolvimentistas" dos governos militares da década de 1970. 
relaciona a intensa vulnerabilidade externa dos países periféricos frente aos centrais, sendo ainda possível identificar a condição dependente de um país a partir de seus níveis de vulnerabilidade externa, o que implica a propensão de estar mais sujeito as crises e abalos financeiros internacionais, ponto crítico na atual conjuntura mundial.

Em termos estritamente econômicos a TD entende que as relações estruturais entre nações estavam para além do campo das relações mercantis de trocas internacionais - como acreditavam os teóricos desenvolvimentistas - se configurando também no movimento internacional de capitais, em especial na forma dos investimentos estrangeiros diretos (IED) e na dependência tecnológica. Esses dois fatores seriam parte manifestas do imperialismo, que ao permear toda a economia e sociedade dependentes, condiciona suas estruturas socioeconômicas, integrando de forma subordinada a economia latino-americana à economia internacional. (DOS SANTOS, 1970, 2015; DUARTE \& GRACIOLLI, 2007; MARINI, 2000).

Não nos parece consensual os limites entre as diferentes percepções que se reivindicavam enquanto "teóricos da dependência", sendo que diferentes autores, como se mostrará no "brief" abaixo apresentam caracterizações distintas, optamos na nossa análise pela especificação construída por Kay (1989), Bresser-Pereira (2005) e Martins (2011). Segundo estes autores a Teoria da Dependência se ramificou em duas matrizes metodológicas principais e distintas: uma metodologicamente marxista e uma que, mesmo influenciada por elementos teóricos marxistas, porém se aproxima de uma visão weberiana, tendo um conteúdo metodológico menos assentado em bases marxianas.

A Teoria da Dependência Marxista (TDM) foi influenciada pelos limites do desenvolvimento na região e pela ofensiva política, social e cultural terceiromundista, propõe-se, utilizando o marxismo ${ }^{4}$, interpretar a formação social latino-

\footnotetext{
${ }^{4}$ O Marxismo na América Latina inicia-se ainda no final do século XIX, com a primeira tradução ao espanhol de O Capital pelo argentino Juan Justo. Esta tradução possibilitou uma expansão do pensamento marxista por meio da difusão dessa obra em grande parte do continente latinoamericano, ainda que, posteriormente, as teses de Justo não pudessem contribuir da mesma forma para a construção do pensamento marxista na América Latina, por associar tanto Marx quanto a sociologia positivista. O marco teórico do marxismo latino-americano se dá na reflexão do peruano José Carlos Mariatégui, considerado o primeiro autor a desenvolver uma reflexão original sobre a realidade da América Latina valendo da metodologia marxista. Ver mais em LOWY, Michael (org.). O marxismo na América Latina: uma antologia de 1909 aos dias atuais. São Paulo: Perseu Abramo, 1999a.
} 
americana, libertando-a das visões dogmáticas vinculadas a chamada III Internacional, cuja expressão na América latina eram as formulações de pensadores vinculados aos Partidos Comunistas ${ }^{5}$.

O capitalismo dependente formado nas economias periféricas está baseado naquilo que Marini (2000, 2005) e Dos Santos ([1970] 2011) denominam de "superexploração do trabalho", manifestação própria de produção e apropriação de mais-valor sustentada em mecanismos de exploração intensiva da força de trabalho ou em formas de rebaixamento do valor da força de trabalho, possibilitando superlucro e transferência de riqueza de uma economia nacional periférica para as economias centrais do capitalismo global. Essa visão teve como principais referencias formuladoras iniciais, as obras de Theotônio dos Santos, Ruy Mauro Marini, Vânia Bambirra e Orlando Caputo, as quais influenciarão fortemente o ambiente intelectual e político, e autores como Florestan Fernandes ${ }^{6}$ dela se aproximarão, ainda que mantenham diferenças de enfoque (MARTINS, 2011).

A outra matriz da dependência se estabeleceu sob a liderança de Cardoso e Faletto (1970), partindo de teses cepalinas, ainda que busque subvertê-las, e sofreu forte influência weberiana, ganhando também projeção regional e internacional, sua tese central seria a impossibilidade da existência de uma "burguesia nacional" na periferia, o que levaria a crer que o desenvolvimento latino-americano só seria possível de uma forma subordinada ou associada. (CARDOSO\&FALETTO, 1970; MARTINS, 2011; DUARTE \& GRACIOLLI, 2007).

De maneira geral, as teorias da dependência significaram um salto na compreensão da realidade latino-americana, uma vez que a problemática do atraso e do subdesenvolvimento era percebida tanto pelos teóricos da modernização

\footnotetext{
${ }^{5}$ Vinculados á politica difundida pela III Internacional Socialista os, ainda nascentes, Partidos Comunistas da América Latina, aderiram à teoria da revolução socialista por etapas e transpuseram esta para o nosso continente um esquema teórico e metodológico construído sobre uma realidade econômica e social distinta da nossa. Em uma tentativa de aproximar a realidade histórica latinoamericana daquela que fora o objetivo da teoria da revolução por etapas, eles identificaram na estrutura social e econômica da América Latina, restos feudais e a existência de uma burguesia comercial, que contrária a burguesia nacional, vinculava-se à oligarquia e com o imperialismo em sua manutenção do domínio de classes do capitalismo americano. Ver Magalhães e Meucci (2011).

6 "Apesar de sua maior proximidade institucional e pessoal a Fernando Henrique Cardoso, Florestan se aproximará muito mais da versão marxista da dependência. Ele desenvolverá uma visão própria do desenvolvimento dependente mesclando os conceitos de estamentos e classes sociais. Para o autor, o capitalismo dependente tinha sua especificidade nas raízes coloniais que levavam as oligarquias dominantes a recusarem a criação de uma ordem social competitiva". Ver mais em MARTINS, 2011.
} 
quanto pelos cepalinos, sob a ótica do nacionalismo metodológico ${ }^{7}$, que vê a economia mundial como um agregado de economias nacionais independentes que se relacionam entre si, principalmente por meio do comércio.

Os problemas que levavam a América Latina e a periferia ao atraso derivavam de heranças históricas, como a colonização, decisões internas equivocadas que beneficiavam grupos parasitários em detrimento da nação. Esses países, ao assumirem sua condição nacional, deveriam superá-los e corrigi-los. Tal retificação não implicava um choque com estruturas internacionais, mas sim com grupos sociais e mentalidades internas (MARTINS, 2011, p.229). As soluções para isto variavam tal como o diagnóstico, mas tinha em comum 0 fato de que significavam o desenvolvimento do poder de decisão nacional a partir do estabelecimento de bases industriais próprias que, paulatinamente, conduziria à convergência com os padrões econômicos, políticos e sociais dos países centrais.

Os teóricos da dependência afirmam ainda, que a estratégia de industrialização baseada no modelo de substituição de importações ao invés de romper com o subdesenvolvimento somente reestabeleceu as condições de dependência sob novos parâmetros, resultando inclusive, em uma pior distribuição de renda, uma demanda interna fraca demais para sustentar a industrialização continuada e crescente internacionalização das economias com a presença das multinacionais nos setores industriais principais (GILPIN, 2002, p.311), o que implicou em elevada perda de capacidade de expansão autônoma da acumulação de capital, principalmente em segmentos do Departamento I da economia (máquinas e meios de produção) ${ }^{8}$.

Martins (2011, p.230) acrescenta que a reprodução da dependência no interior da divisão internacional do trabalho hierarquizada, se dá enquanto trajetória

\footnotetext{
${ }^{7}$ Termo usado primeiramente por Hermínio Martins em seu artigo Time, Theory and Sociology (1974). $\mathrm{Na}$ fundamentação teórica do nacionalismo metodológico, a nação/país é vista como uma "unidade autossuficiente e inserida em um ambiente internacional indiferenciado" (MEDEIROS, 2010). Ou ainda, seria uma abordagem em que "as trajetórias dos países são explicadas essencialmente por estratégias implementadas por seus estados nacionais". (MEDEIROS, 2010). Ver mais em Vieira (2013).

${ }^{8}$ Marx categorizou a economia em dois departamentos onde Departamento I corresponde aos bens de capital e Departamento II corresponde aos bens de consumo. A relação entre departamentos econômicos procede a maior ou menor troca entre insumos tecnológicos no interior das próprias fronteiras nacionais, de tal maneira que a presença de do Departamento I com elevado grau de autonomia e definição de engenharia e estrutura reprodutiva garante a economia em questão maior grau de poder de decisão econômico e reduz expressivamente sua vulnerabilidade externa, conferir Mandel (1985), Harvey (1990) e Gonçalves (2005).
} 
subordinada dentro da economia mundial. $\mathrm{O}$ que define estruturalmente a dependência é o grau de subordinação e limitação tecnológico que estabelece barreiras a expansão autônoma e geral do departamento I da economia, permanecendo atrofiado e subordinado ao exterior.

\section{A TEORIA DA DEPENDÊNCIA MARXISTA E A CONSTRUÇÃO DA INTERPRETAÇÃO RADICAL DO CONTEXTO LATINO AMERICANO}

A versão marxista da teoria da dependência (TDM) surge como uma crítica às concepções dos Partidos Comunistas e ao pensamento desenvolvimentista. Essa visão, buscando a identidade do capitalismo dependente em sua articulação especifica à economia mundial, rompe com o reducionismo metodológico e se propõe a reinterpretar o próprio desenvolvimento capitalista, gerando novas categorias de interpretação da realidade latino-americana, sendo que o desenvolvimento desta região deveria ser compreendido a partir do duplo vetor: ciclo de reprodução do capital localizado nessas formações econômicas e expansão da economia mundial capitalista.

A categoria de dependência permite visualizar a situação interna dos países periféricos como parte da economia global. Para a escola marxista a teoria imperialista foi desenvolvida como um estudo do processo de expansão dos centros capitalistas e de sua dominação mundial. Desenvolver a teoria das leis do desenvolvimento interno nos países que são o vetor dessa expansão e naqueles que são governados por elas, se faz necessário. Este exercício transcende a teoria do desenvolvimento que se propõe explicar a situação de países subdesenvolvidos como resultado de sua lentidão ou fracasso em adotar os padrões de eficiência característicos dos países desenvolvidos.

Apesar da teoria do desenvolvimento capitalista admitir a existência de uma dependência externa, ela é incapaz de perceber o desenvolvimento da maneira como a presente teoria o compreende, como consequência e como parte do processo de expansão global do capitalismo - parte necessária e intrinsecamente vinculada a esse processo (DOS SANTOS, 2011).

A partir da análise do processo de constituição de uma economia global formada pela interação de economias nacionais em um mercado mundial nota-se que as relações produzidas por esse mercado são desiguais e combinadas desiguais porque o desenvolvimento de certas partes do sistema ocorre em 
detrimento de outras partes- uma vez que as relações comerciais baseiam-se no controle monopólico do mercado, que acarreta a transferência do excedente gerado nos países dependentes para os países dominantes. As relações financeiras, sob a ótica das economias centrais, baseiam-se em empréstimos e na exportação de capital, o que lhes permite receber juros e lucros, aumentando dessa forma, seu excedente doméstico e fortalecendo seu controle sobre as economias dos outros países.

Para os países dependentes, tais relações representam uma exportação de lucros e juros que leva junto parte do excedente gerado domesticamente e conduz a uma perda do controle sobre seus próprios recursos produtivos. Nesse sentido, para que essas relações desvantajosas sejam permitidas, os países dependentes têm de gerar grandes excedentes, não através da criação de tecnologias de nível mais elevado, mas pela superexploração da força de trabalho. Isto resulta em limitação do desenvolvimento de seu mercado interno e de sua capacidade técnica e cultural, bem como da saúde moral e física da população. Este fenômeno denomina-se desenvolvimento combinado, uma vez que é a combinação das desigualdades e a transferência de recursos dos setores mais atrasados e dependentes aos mais avançados e dominantes, o que explica e acentua a desigualdade, e a transforma em um elemento necessário e estrutural da economia global.

Segundo Marini (2000 p.109-113), os países latino-americanos relacionam-se com os centros capitalistas por meio de uma estrutura estabelecida a partir de uma divisão internacional do trabalho, na qual as relações de produção das nações periféricas são transformadas ou recriadas para garantir a reprodução ampliada da dependência. Do ponto de vista do centro para a periferia, a participação da América Latina no mercado internacional contribuiu para que o eixo da acumulação dos países imperialistas se desloque da produção da mais-valia absoluta para a maisvalia relativa, de modo que a produção passa a depender muito mais da produtividade do trabalho do que da extensão da exploração do mesmo. Vale notar que nas últimas duas décadas, as características da dependência voltam a acirrar as contradições entre um centro produtor de elevada tecnologia e uma periferia, cada vez mais dispersa, produtora de recursos naturais, um padrão de reprimarização produtiva evidenciada nas maiores economias latino-americanas (OSÓRIO, 2012; TRINDADE, 2017). 
Do ponto de vista da relação centro-periferia, percebe-se considerável contradição, um "intercâmbio desigual", pois os países dependentes exportam produtos básicos que não requerem a introdução de tecnologia desenvolvida internamente para expansão da acumulação, onde a produção se fundamenta em mecanismos de superexploração da força de trabalho ou na extração intensiva de recursos naturais. Assim, as burguesias das economias dependentes frente ao processo de troca desigual encontram no aumento da exploração do trabalho um mecanismo que permite o aumento da massa de valor disponível para a exportação. Assim, o "aumento da intensidade do trabalho aparece, nesta perspectiva, com um aumento de mais-valia, conseguida através de uma maior exploração do trabalhador e, não, do incremento de sua capacidade produtiva" (MARINI, 2000, p.123-124).

Deste modo, a superexploração do trabalhador é uma característica essencial da produção nos países dependentes. Pode ser entendida inicialmente pelo fato de que sua produção se determina pela baixa composição orgânica do capital, ao passo que países de base industrial têm composição orgânica mais elevada e crescente, portanto, passam por um processo de queda na taxa de lucro, levando estes últimos a buscarem mecanismos de ampliação da mais-valia como forma de compensar tal queda (MARINI, 2005).

Dadas as condições para submeter o trabalhador a tal situação, pode-se concluir que a execução dos três mecanismos descritos - 0 aumento da intensidade do trabalho, o aumento da jornada e a redução do consumo do operário, além de seu limite normal - têm suas características essenciais, "no fato em que se nega ao trabalhador as condições necessárias para repor o desgaste de sua força de trabalho (...) [o que significa] que o trabalhador se remunera por baixo de seu valor $\mathrm{e}$ correspondem, então, a uma superexploração do trabalho (MARINI, 2000, p.126).

A TDM sofreu significativa influência das ideias de Paul Baran e André Gunder Frank, no que diz respeito à apropriação internacional dos excedentes dos países periféricos e subdesenvolvidos por meio de monopólios comerciais, produtivos e financeiros. Para Paul Baran (1957), o excedente pode ser visto de três maneiras, são elas: o excedente econômico real, o potencial e o planejado. O excedente real está relacionado a toda massa de recursos da economia disponível, uma vez deduzido o consumo; o potencial corresponde à massa de recursos que poderia ser dedicada ao investimento, uma vez deduzidos o desemprego, o subemprego ou consumo suntuário dos capitalistas e da burocracia governamental; 
e por fim, o excedente planejado, que seria aquele desenvolvido em uma sociedade socialista que eliminaria o lucro como princípio de organização social (MARTINS, 2011, p.237).

Tradicionalmente, as sociedades separam seus recursos naqueles destinados ao consumo e aqueles dedicados à formação da poupança e ao investimento, que corresponde ao excedente econômico. Entretanto, para Paul Baran, os países subdesenvolvidos teriam seu excedente apropriado pelos investimentos estrangeiros e pelo sistema financeiro e comercial internacional. Nesse sentido, a vinculação prematura à economia internacional conduz a excessos de importações que se acentuam através da manipulação de preços praticada na relação entre matrizes e filiais. Por outro, Frank (1973) desenvolve seu trabalho centrado em uma concepção sistêmica que envolve a divisão do mundo em metrópoles e satélites nacionais, regionais e locais. Dentro dessa abordagem, a condição de metrópole ou satélite seria determinada pela capacidade positiva ou negativa de apropriar-se dos excedentes gerados no mundo por meio das relações econômicas internacionais que envolviam não apenas o comércio, mas também a circulação de capitais.

Nesse contexto, Frank (1973) procurou basicamente demonstrar que o subdesenvolvimento é uma criação e recriação do imperialismo, uma vez que as metrópoles se apropriam sistematicamente do excedente produzido pela exploração dos trabalhadores da periferia, se apropriando de todo o potencial de acumulação destes últimos. Para Frank, a América Latina tem sua essência centrada no capitalismo, ainda que seja um tipo específico, gerado pelo tipo de colonização europeia que implantou na região um modelo capitalista exportador de produtos primários.

Nesse sentido, o subdesenvolvimento, para Frank (1973, p.31) não ocorre devido à sobrevivência de instituições arcaicas e à escassez de capital nas regiões que permaneceram isoladas do fluxo da história mundial. Pelo contrário, ele foi e é gerado pelo mesmo processo histórico que gerou também o desenvolvimento econômico: o desenvolvimento do capitalismo. Argumenta ainda que a pesquisa histórica demonstra que o subdesenvolvimento contemporâneo é em grande parte produto histórico das relações econômicas e de outra natureza, passadas e presentes, entre os satélites subdesenvolvidos e os países metropolitanos atualmente desenvolvidos. 
Os elementos condicionantes da dependência provocam uma forte saída estrutural de recursos, acarretando recorrentes problemas de estrangulamento externo e restrições externas ao crescimento. Com isso, a única maneira que a acumulação de capital interna à economia dependente tem para prosseguir seria aumentar a sua produção de excedente, mesmo que uma parcela crescente desse excedente seja apropriada e, portanto, acumulada, externamente, o restante pode sustentar uma dinâmica de acumulação interna, ainda que restringida e dependente.

Teoricamente, o intercâmbio de mercadorias exprime a troca de equivalentes, cujo valor se determina pela quantidade de trabalho socialmente necessário que as mercadorias incorporam. Dessa forma, na prática se observam diferentes mecanismos que permitem realizar transferências de valor passando por cima das leis de intercâmbio e que expressam na maneira como se fixam os preços de mercado. (MARINI, 2005, p.150).

É possível distinguir, segundo Dos Santos (2011), três formas históricas de dependência condicionadas, primeiramente, pelas próprias leis de desenvolvimento da economia mundial; pelo tipo de relação econômica dominante nos centros capitalistas e pelos modos como estes se expandem e por fim, por tipos de relações econômicas existentes nos países periféricos que são incorporados à situação de dependência no âmbito da rede de relações econômicas internacionais geradas pela expansão capitalista.

A primeira delas seria a dependência colonial, caracterizada pela exportação de produtos in natura e onde o capital comercial e financeiro, associado ao Estado colonialista, dominava as relações econômicas dos europeus e das colônias. A segunda seria a dependência financeiro-industrial que teria se consolidado no fim do século XX, e caracteriza-se pela dominação do grande capital nos centros hegemônicos, cuja expansão acontecia através de estímulo á produção, nos países periféricos, de matérias-primas e produtos agropecuários para consumo próprio. Isto acarretou o desenvolvimento, nos países dependentes, de uma estrutura produtiva interna dedicada á exportação de tais produtos com rígida especialização produtiva e monocultura em regiões internas.

Esses condicionamentos impostos por estas duas formas iniciais de dependência, acarretaram a existência de um mercado interno restrito por quatro fatores: i) maior parte da renda nacional derivava-se da exportação; ii) a força de trabalho era submetida a várias formas de super exploração, o que limitava sua 
capacidade de consumo; iii) parcela do consumo desses trabalhadores se dava através da economia de subsistência, que funcionava como um complemento de sua renda e como um refúgio em períodos de depressão econômica; e iv) uma grande parte do excedente acumulado era remetida ao exterior sob a forma de lucros, limitando não apenas o consumo interno, mas as possibilidades de reinvestimento.

Consolidada nos anos 1950, a terceira forma de dependência, a tecnológicoindustrial, baseava-se em corporações multinacionais que começaram a investir e instalar indústrias dentro das economias dependentes visando o mercado interno destes países. Dessa forma, a possibilidade de gerar novos investimentos depende da existência de recursos financeiros em moeda estrangeira para a aquisição de maquinário e matérias-primas não produzidas domesticamente. Esta aquisição está limitada por: i) recursos gerados pelo setor exportador; ii) pelo monopólio de patentes.

A consequência da primeira limitação é a necessidade de preservar o setor exportador tradicional gerador de divisas. A segunda limitação se dá por conta de que o maquinário e os insumos necessários ao desenvolvimento industrial dos países periféricos são produzidos em um mercado internacional altamente concentrado, o que eleva seus preços. Há também a necessidade de pagamentos de royalties para a utilização de produtos e tecnologias patenteadas, ou, na maioria dos casos, as indústrias produtoras convertem esses produtos em capital e os introduzem nas economias dependentes na forma de seus próprios investimentos, através da instalação de filiais. Isto faz com que os fluxos de recursos sejam fortemente desfavoráveis para os países dependentes, o que explica sua escassez de divisas e permanentes crises cambiais.

Dessa forma, todas as formas de dependência correspondem a uma situação condicionada não apenas pelas relações internacionais desses países, mas também por suas estruturas internas. Assim identificam-se três condicionantes históricoestruturais da dependência: a superexploração do trabalho, como fator estrutural central da dinâmica de acumulação destas nações; o fator empírico recorrente de perda nos termos de troca, ou seja, a redução dos preços dos produtos exportados pelas economias dependentes em face dos preços dos produtos industriais ou insumos tecnológicos com maior valor agregado importados dos países centrais, em um verdadeiro processo de transferência de valores; por fim, a remessa de 
excedentes dos países dependentes para os avançados, sob a forma de juros, lucros, amortizações, dividendos e royalties (CARCANHOLO, 2008).

Marini $(2000,2005)$ argumenta que a superexploração da força de trabalho não coloca, em princípio, empecilhos para a acumulação interna de capital, ao restringir o consumo da força de trabalho, porque sua dinâmica de realização pode depender do mercado externo e/ou de um padrão de consumo que privilegie as camadas média e alta da população. Entende-se que "a condição de dependência é estrutural (própria da lógica de acumulação mundial) e tende a se aprofundar, justamente porque esses condicionantes são reforçados por essa própria lógica" (CARCANHOLO, 2008, p.257). A partir dessa dinâmica de acumulação de capital, o capitalismo dependente pode crescer, contornando sua restrição externa. Entretanto, essa dinâmica traz consigo consequências inevitáveis da dependência: distribuição regressiva da renda e da riqueza, associada a uma marginalidade e violência crescentes.

\section{ECONOMIA CAPITALISTA MUNDIAL E A RENOVADA DEPENDÊNCIA LATINO-AMERICANA}

O processo de globalização, a crise da dívida dos anos 1980 e a dinâmica econômica passiva latino-americana a partir da década de 1990 aprofundaram as precárias condições de desenvolvimento autônomo de suas economias nacionais, seja pela desnacionalização de segmentos expressivos da indústria, seja pela elevação da vulnerabilidade externa nos principais aspectos a ser considerados: na capacidade produtiva (elevação das ECE e maior dependência de investimento externo direto), tecnológica (baixa capacidade de estruturação de um sistema nacional de inovação e baixa dinâmica tecnológica) e financeira (investimentos financeiros, empréstimos e financiamentos) ${ }^{9}$.

Vale frisar que as específicas condições econômicas enfrentadas na década de 1990, fruto da transição da ISI ao neoliberalismo e assim o reduzido papel do Estado na economia compuseram o quadro mais geral. Esta conjuntura de

\footnotetext{
${ }^{9}$ A noção de vulnerabilidade externa refere-se ao grau de maior ou menor poder de resiliência de uma economia a pressões, fatores desestabilizadores e choques externos. Essa noção é plenamente ajustável a categoria socioestrutural de dependência, vista enquanto atributo dialético central para se pensar as articulações entre as diversas formações econômicas capitalistas e o poder de autonomia relativa de cada uma sobre o sistema capitalista internacional. A vulnerabilidade externa em termos econômicos poderá se manifestar nas dimensões financeira, comercial, tecnológica e produtivo-real (GONÇALVES, 2005, p. 14).
} 
alterações econômicas e sociais na AL foi acompanhada por um forte refluxo teórico do pensamento latino-americano critico, especialmente desde fins da década de 1980 a Teoria da Dependência passou a ter menor influência, inclusive academicamente, como ressaltou Vernengo $(2006)^{10}$.

Nas décadas de 1980 e 1990 firma-se na América Latina uma percepção teórica centrada na noção de que são os "desequilíbrios internos" os únicos responsáveis pelos limites do desenvolvimento no continente. Esta visão chamada de "endogenista"11 irá atacar fortemente as teorias da dependência, afirmando que são os fatores endógenos ou internos da realidade latino-americana que condicionam as especificidades do seu capitalismo. Como pondera Martins (2011, p. 259) estas formulações ignoravam o peso e a forma da "articulação da América Latina à economia mundial", de outro modo abandonava-se a perspectiva de que as relações capitalistas eram, antes de tudo, relações de poder econômico imperialista que produzem ao mesmo tempo desenvolvimento e subdesenvolvimento como componentes de uma mesma totalidade.

Cardoso (1993, p. 235) ao renunciar a Teoria da Dependência, passa a entender a possibilidade modernizante do capital internacional na sua nova forma globalizada, o que denomina de "novo mundo", em seus termos, ainda anteriores a sua completa conversão neoliberal, observa que este capitalismo do século XXI permitiria "o ressurgimento de forças localista, de valores culturais-nacionais (como a língua) e da religião, ao lado da globalização das forças produtivas e da economia".

Ao assumir o governo do Brasil na segunda metade da década de 1990 (1996), Cardoso é responsável pela completa integração da economia brasileira aos marcos do Consenso de Washington ${ }^{12}$, o que implicava "aceitar os novos marcos estruturais que se originam dos centros dominantes para buscar dentro deles a

\footnotetext{
${ }^{10}$ Marini (1993) observa que diferentemente das décadas de 1960 e 1970 quando se observou forte "florescimento" teórico, a partir dos anos 1980 observa-se uma "pobreza teórica e um formalismo acadêmico" na América Latina marcadamente subordinada ao academicismo norte-americano e europeu, conferir também Prado (2013, p. 12).

${ }_{11}$ Entre os principais autores endogenistas vale citar: Agustin Cueva, Francisco Weffort e Ciro Flamarion Cardoso, para uma detida análise conferir Martins (2011, p. 259) e Dos Santos (2015, p. 28).

${ }^{12}$ O Consenso de Washington se afirma na década de 1990 e propunha o desmonte de qualquer política industrial e protecionista, girava em torno de alguns pilares que vão ser o eixo das políticas macroeconômicas neoliberais das próximas décadas, especialmente o equilíbrio fiscal, a desregulamentação da economia, a privatização de empresas públicas e a apreciação cambial. No Brasil, entre os que mais defendem o neoliberalismo estão autores vinculados a antiga escola da dependência reformista, entre os quais o próprio Cardoso (1996, 1998), Goldenstein (1994), além de autores monetaristas, como Franco (1999).
} 
melhor inserção" (Martins, 2011, p. 253). A interpretação que se estabelece desde então será que a maior mobilidade do capital financeiro possibilitará as sociedades latino-americanas reestabelecer seus padrões de desenvolvimento, com maior crescimento econômico, mesmo que sob condições subordinadas, sendo que a abertura dos mercados nacionais a circulação internacional de mercadorias e fluxo de capitais seriam suficientes para uma nova retomada desenvolvimentista (GOLDENSTEIN, 1994; MARTINS, 2011).

Porém as alterações ocorridas já nas décadas de 2000 e 2010 recolocaram o debate da dependência e o retorno das análises radicais do desenvolvimento latinoamericano, sendo que esta retomada se dá centralmente a partir da influencia dos autores marxistas, especialmente Theotônio dos Santos, Ruy Mauro Marini, Vânia Banbirra e Jayme Osório. Vale esclarecer que um dos fatores que leva a influência e retomada das análises sociais e econômicas latino-americanas da dependência desde um enfoque marxista, refere-se ao completo encolapsamento da visão da "dependência associada", que como já explicitado devia-se, principalmente, as formulações de Cardoso (1970, 1976, 1993).

Aspecto de forte influência nesta retomada será a construção de categorias que permitem a maior interação do pensamento da dependência com as chamadas Teorias do Sistema Mundo, especialmente as de "Padrão de Reprodução do Capital", categoria que permite a autores como Jaime Osório e Carlos Martins darem continuidade as formulações da dependência ${ }^{13}$. No texto que segue busca-se estabelecer alguns aspectos centrais da interpretação da Teoria da Dependência Marxista em relação a economia mundo capitalista e o processo de globalização e afirmação do neoliberalismo.

De forma geral, Wallerstein (1987) defende que a abordagem do sistemamundo estude o surgimento, desenvolvimento e desintegração de sistemas sociais históricos, pesquisados através do método comparativo. Sistemas sociais históricos são conjuntos de estruturas, simultaneamente sistêmicos e históricos, cuja coexistência e sucessão representam o próprio conteúdo do mundo social (VIEIRA, 2008). A Teoria do Sistema Mundo compreenderia, assim, um conjunto variado de formulações que se alimentam da dinâmica histórica para visualizar processos de

${ }^{13}$ Para uma detida, mesmo que ainda parcial, revisão bibliográfica da retomada do pensamento marxista dependentista no Brasil, conferir Prado (2013), no México, Osório (2014) e na Argentina, Asterita (2013). 
longo prazo de reorganização da economia capitalista sobre bases novas e mais amplas, assim como define o moderno sistema mundial enquanto forma da superestrutura política e social plenamente adequada ao desenvolvimento do capitalismo, buscando compreender seus movimentos cíclicos e fatores que impulsionam expansão e crise dos centros hegemônicos no âmbito da economia mundo capitalista (WALLERSTEIN, 1987; ARRIGHI, 1996, 2008; MARTINS, 2011).

É possível deduzir que a versão neomarxista enfatiza a importância do movimento global do capital como central das situações de dependência, porém sem descurar do papel das forças internas desse movimento. É fato que as implicações teóricas da teoria da dependência marxista ainda estão por se desenvolver. Nesse sentido, na seção final analisa-se brevemente a relação entre a teoria do sistema mundo e a teoria da dependência marxista, estabelecendo a hipótese de que a retomada da teoria da dependência somente tem sentido se tratada como condição teórica para tratamento da dinâmica capitalista mundial.

A expansão mundial do capital e a configuração do capitalismo enquanto economia-mundo se processa desigualmente em termos territoriais, não havendo "convergência" como processo econômico, mas o estabelecimento de diferentes hierarquias geoeconômicas, em conformidade a uma dinâmica de desenvolvimento desigual e combinado. A divisão internacional do trabalho estabelece três zonas na economia mundial: o centro, a semiperiferia e a periferia, sendo que essa divisão aparece funcional para garantir a apropriação de mais-valia pelos centros e novoscentros, permitindo o desenvolvimento do capitalismo nas regiões de liderança tecnológica. Wallerstein (1987) condicionou a possível transição de periferia e semiperiferia para centro, a "coexistência de dois fatores: uma política interna de catching-up [e] o apoio dos centros financeiros do sistema mundial".

Entretanto, vale denotar que as relações entre economias capitalistas centrais e periféricas se mantém pela transferência ou vazão líquida de valor para os países metropolitanos, seja pelos mecanismos clássicos de remessas de dividendos, juros e ordenados pagos aos diretores das grandes companhias imperialistas e aos débitos crescentes dos países subdesenvolvidos, mas também pelo agravamento da troca desigual (Mandel, 1985; Marini, 2008; Dos Santos, 1993).

Dos Santos $(1970,1978,1993)$ estabelece uma série de nexos analíticos importantes com a teoria do sistema mundial, ao destacar a existência de uma economia mundial em expansão como o elemento central da acumulação de capital 
e situar o mundo como objeto de análise condicionante para qualquer investigação regional ou nacional, o que torna a dependência uma das características do sistema mundo capitalista. Em particular sua obra "Imperialismo e dependência" (1978) ao analisar a crise da hegemonia imperialista dos Estados Unidos, e os projetos em luta para a reconversão da economia mundial, antecipa aspectos importantes da perda de capacidade diretiva internacional dos EUA e como as mudanças tecnológicas em curso terão importância na "nova dependência" tecnológica-industrial que se imporá as economias latino-americanas.

Segundo este autor a dependência a partir da segunda metade do século $X X$ estaria fundada numa situação de compromisso entre os interesses que movem as estruturas internas dos países dependentes e as do grande capital internacional, o que implica numa profunda internalização dos interesses das empresas transnacionais e nova limitação ao grau de autonomia das economias e sociedades periféricas, inclusive quanto aos aspectos democráticos, o que denomina de democracia restringida.

Duas grandes tendências se estabelecem no sistema capitalista mundial a partir de meados dos anos 1990:

i) O desenvolvimento da revolução científico-técnica que no entendimento de Marini (2008), determina a contradição entre o aumento da produtividade e a maisvalia extraordinária, isso ao reduzir a massa de valor empregada na força de trabalho a uma parte cada vez menor do processo produtivo, tornando a economia de trabalho estabelecida pela inovação tecnológica exígua para valorizar a quantidade de mercadorias gerada pelo aumento da produtividade.

ii) A tecnologia nas economias nacionais permite significativamente 0 barateamento dos preços, em função da elevação do nível de produtividade, sendo que a adoção crescente da automação diminuiu drasticamente o emprego industrial, agravando ainda mais as condições de expansão do exército industrial de reserva e a subutilização de força de trabalho, ao lado da intensificação da exploração dos trabalhadores (Dos SANTOS, 1978, 1993; BAMBIRRA, 2015), o que levará a autores como Marini (2008) e Martins (2011) a propugnarem que os mecanismos de "superexploração da força de trabalho" se generalizariam inclusive para economias centrais.

O resultado disso é a tendência à queda de preços e a crise da mais-valia extraordinária fazendo com que o capital reaja a esta crise de quatro formas: i) 
apropria-se dos recursos públicos do Estado, impulsionando a dívida pública para sustentar lucros extraordinários que não se realizam integralmente pelo ciclo específico do capital produtivo; ii) privatização de empresas públicas, estabelecendo uma forma de acumulação fundada na desapropriação de capital estatal; iii) transfere-se parcialmente para países que ofereçam força de trabalho com qualificação próxima e significativamente mais barata que a dos países centrais; iv) apoia-se na sobrevalorização cambial estabelecida pelo governo estadunidense, que permite abalizar as diferenças entre os custos em moeda nacional e a realização de mercadorias em dólar, via exportação, restituindo parcialmente o lucro extraordinário por intermédio de vultuosos déficits comerciais dos Estados Unidos.

Para os autores da TDM a mundialização da revolução científico-técnica e a globalização estabeleceram mudanças que levaram a uma intervenção estatal totalmente distinta da que se determinou durante o período longo de crescimento econômico dos anos 1940 a 1960. Na fase dourada do keynesianismo, este tipo de intervenção favoreceu o desenvolvimento da produtividade, e o ciclo produtivo do capital garantia com razoável autonomia a sustentação dos lucros extraordinários. Entretanto, o novo período de crescimento longo, que se estabeleceu a partir de meados dos anos 1990, criou a lógica de intervenção estatal baseada na sustentação de valores fictícios de ativos em detrimento do desenvolvimento da produtividade. Esta nova lógica manifesta-se pela drástica elevação da dívida pública, pelas baixas taxas de investimento e pelo aumento das taxas de desemprego.

Vale observar que as reformas econômicas globais recentes, nas décadas de 1990 e 2000, basearam-se em acentuada racionalização empresarial que acompanhou o o "receituário" neoliberal ${ }^{14}$, um conjunto de proposições dominantes quanto à reorganização econômica para uma série de economias nacionais que aprofundaram o grau de dependência ou subordinação dessas economias a ordem hegemônica global. Os pilares do 'modelo neoliberal' são: (1) abertura comercial; ii) desregulamentação financeira; iii) privatização de empresas públicas e; iv) desregulamentação (flexibilização) das relações de trabalho ${ }^{15}$.

\footnotetext{
${ }_{15}^{14}$ Para uma minuciosa apreciação do neoliberalismo conferir Dos Santos (1993); Harvey (2008).

15 Quanto ao entendimento das políticas de desregulamentação macroeconômica neoliberais e o estabelecimento de uma "era da globalização" conferir: IPEA (2010a).
} 
Martins (2011, p. 146-147) observou, de forma correta, um conjunto de contradições presentes no Neoliberalismo, sendo que parcela do discurso doutrinário é negado pelo exercício real de suas políticas econômicas, especialmente a relação entre neutralidade estatal no discurso vis-à-vis expansão dos déficits públicos e aceleração da divida pública ${ }^{16}$. $\mathrm{O}$ autor observa cinco pontos característicos do neoliberalismo enquanto "ideologia da crise do sistema mundial", reforçando os pontos macroeconômicos já expostos:

a) A maior intervenção financeirizada do estado, com elevação do esforço fiscal para fazer frente a elevação da divida pública.

b) O reforço ao discurso do "territorialismo" e a noção de que políticas de desenvolvimento devam ser pontuais e locais, como negação a políticas nacionais e de afirmação de capacidades soberanas de desenvolvimento. Aspecto que reforça a disputa interna a cada nação pelo fluxo de investimento, minando, muitas vezes, a capacidade fiscal local em favorecimento aos capitais empresariais.

c) Imposição pela OMC (Organização Mundial do Comércio) de normas tarifárias e para tarifárias que sufragam os "princípios da concorrência, abertura comercial e flexibilidade cambial" desiguais e fortemente assimétricos, diminuindo a capacidade de negociação dos países periféricos e reforçando os circuitos comerciais norte-norte. A diminuição de barreiras tarifárias associadas a acordos multilaterais realizados no âmbito da $\mathrm{OMC}$ e à proliferação de acordos regionais favoreceu a globalização de processos produtivos, reforçando formas de subcontratação e a crescente externalização produtiva em diversos setores ${ }^{17}$, como antes exposto.

d) Elevação dos desequilíbrios financeiros e comerciais. A financeirização se processa tanto pelo reforço do caráter rentista da estrutura econômica, compreendendo a expansão da massa de capital fictício no sistema de crédito, como pela flexibilidade cambial e liberalização da conta de capital com consequente

\footnotetext{
${ }^{16}$ Dos Santos (1993, p.135) ressalta que no "auge do neoliberalismo, sob os governos Thatcher e Reagan, não diminuiu a intervenção estatal, mas pelo contrário a aumentou”. Os indicadores que ele utiliza são basicamente referentes o aumento do déficit fiscal e a elevação da divida pública, tendo como razões a expansão dos gastos militares, o maior serviço da divida e a redução de impostos para a classe de altas rendas.

${ }_{17}$ Como observa estudo do Ipea (2010b, p. 371) os acordos promovidos sob auspícios da OMC, dos EUA (US offshore Assembly Programme - OAP) e da União Europeia (Outward processing Trade), tinham forte identificação com as "empresas multinacionais (EMN) por conta de sua maior capacidade financeira para arcar com a logística de um processo produtivo segmentado" territorialmente. O objetivo último dessa dinâmica consiste tanto na diminuição dos custos salariais, quanto no aproveitamento de expertises locais, alavancando a rentabilidade das EMN.
} 
instabilidade das transações correntes e balanço de pagamentos das economias periféricas e, nos últimos anos das próprias economias centrais.

e) Desmonte das políticas sociais, flexibilização dos mercados de trabalho e desestruturação do Estado de bem-estar social, componentes necessários ao restabelecimento do Exército Industrial de Reserva e ao estabelecimento da ideologia liberal-conservadora.

Nas décadas de 1990 e 2000, as alterações são sensíveis, conformando políticas externas da economia hegemônica com o objetivo de buscar superávits comerciais que pudessem, mesmo de forma limitada, recompor a capacidade de financiamento estadunidense. Será neste contexto que se imporá as economias latino-americanas e, especialmente, aos países mais industrializados da região (Brasil, México e Argentina) uma agenda que sedimentará uma trajetória de desestruturação industrial ou de reprimarização de suas bases exportadoras. O núcleo das políticas estabelecidas, desde o grupo de Santa Fé, constituía na valorização cambial das moedas das economias periféricas, privatização dos recursos estatais para gerar liquidez e elevação das taxas de juros, para repassar aos capitais financeiros internacionais (TRINDADE et al. 2016; TRINDADE\&OLIVEIRA, 2017)

Dos Santos (1993, p. 142-143) chamou atenção para que poucos estudiosos perceberam as alterações sensíveis que a nova política econômica estadunidense para as economias periféricas latino-americanas reservaram: "abriu caminho para uma nova fase das economias da região, baseadas em moedas fortes, déficits comerciais e atração de capitais financeiros". Esse tripé de política de comércio internacional persistirá, com alguma variação conforme o país, em sua quase totalidade até meados da década de 2000, constituindo elemento explicativo importante para o aprofundamento da vulnerabilidade externa brasileira e latinoamericana em geral.

As modificações mais recentes no quadro da DIT foi resultado de forte aumento da qualidade e do valor da força de trabalho de um conjunto principalmente asiáticos- de países periféricos. Como mostra Maddison (1997, p. 115-7) a escolaridade da população entre 15 e 64 anos em países como a China avançou em mais de cinco vezes no período de 1950 a 1992, sendo que o nível de qualidade do ensino possibilitou uma progressiva elevação da produtividade do trabalho, no caso da China, por exemplo, entre 1973 e 1992 a taxa anual de 
crescimento foi de $4,1 \%$. Outros países asiáticos tiveram comportamento semelhante, a Coréia do Sul teve um acréscimo na escolaridade da PEA de mais de quatro vezes nas quatro décadas seguintes a Guerra da Coréia e a sua produtividade teve uma média anual de crescimento anual de 5,2\% no período estudado pelo autor ${ }^{18}$.

Convém ponderar sobre o caso da China, cuja importância para a dinâmica da balança comercial e o perfil no médio prazo do desenvolvimento brasileiro e latino-americano são inegáveis, na medida em que o modelo chinês de acumulação impacta favoravelmente a estrutura mundial de preços dos produtos primários, ao impulsionar sua demanda, e negativamente a dos produtos manufaturados, ao expandir sua oferta e competição, o que favorece, momentaneamente, de um lado, ao balanço de pagamento dos países periféricos e semiperiféricos, contendo provisoriamente seus desequilíbrios financeiros e o descenso no sistema mundial. Por outro lado, contribui para a reprimarização de suas pautas exportadoras e a deterioração da inserção internacional, agravando no médio e longo prazo a vulnerabilidade externa das economias latino-americanas ${ }^{19}$.

Os autores atuais da TDM consideram que há uma conexão profunda entre crescimento econômico e capacidade de disputar espaço no mercado internacional a partir de quatro fatores coordenados: i) a maior intensificação tecnológica da produção nacional; ii) a melhor organização das redes produtivas e de negociação comercial, estruturando uma governança nacional em relação ao comércio internacional; iii) pelo permanente estabelecimento de políticas macro-prudenciais, seja cambiais, fiscais ou de proteção ao mercado interno e; iv) reforçando políticas de bloco regional, garantindo capacidade de escala produtiva e poder de intervenção sobre espaços econômicos superiores aos limites nacionais. No caso latinoamericano pouco se estabeleceu dos quatro fatores assinalados, mesmo no caso do

\footnotetext{
${ }^{18}$ O estudo mostra que a América Latina como um todo não teve o mesmo comportamento correlacionado crescimento médio educacional e elevação da produtividade. No caso brasileiro, mesmo havendo uma elevação da escolaridade da população economicamente ativa, que triplica em média no período do pós-guerra, passando de 2 anos para 6,4; porém evolução da produtividade é muito inferior a apresentada nos países asiáticos, sendo somente de 0,9\% no período de 1973 a 1992.

${ }^{19}$ Os dados da WTO mostram o crescimento explosivo - de 9,7\% em 2000 para 16,8\% em 2008 - da participação da Ásia nas exportações da América do Sul e Central para a região asiática ${ }^{19}$. No caso brasileiro, as exportações para a China representaram em 2011, 17,31\% do montante total exportado pelo país, enquanto em 1990, representava 1,22\%. Em termos de blocos econômicos, comparando os anos 2000 e 2011, nota-se, no que tange às exportações, que União Europeia, Estados Unidos e Mercosul perderam participação, enquanto a Ásia para a ser o grande destaque.
} 
Mercosul $^{20}$, sua capacidade organizativa e de governança centrada nos principais países (Brasil e Argentina) sempre se mostraram bastante frágeis, quanto aos demais fatores vale notar a perda da capacidade tecnológica de países como Brasil e México, assim como ao longo das últimas décadas a inexistência ou fragilidade das políticas macro-prudenciais.

Vale observar em relação a intensidade tecnológica do comércio exterior de diversas economias periféricas e semiperiféricas, a forte presença ou influência de fenômenos batizados de "redes internacionais de produção" ou que está associado ao formato globalizado de produção das transnacionais, de tal forma que a fragmentação do processo produtivo influencia nas pautas exportadoras daquelas economias o maior peso relativo de produtos classificados como de média ou elevada tecnologia, porém com baixa influência em termos de valor agregado, geração de emprego e disseminação tecnológica (Ipea, 2010a e 2010b; MARTINS, 2011).

Derivado dos processos possíveis de estratégia de desenvolvimento ou sua negatividade abrem-se duas possibilidades, ressaltadas por Martins (2011, p. 157) e historicamente visualizadas nas experiências nacionais tratadas por Chang (2004): "a dependência e seu aprofundamento com intensificação da superexploração e a marginalização da fronteira tecnológica; e o desenvolvimento nacional que rompe com a dependência e a superexploração e se aproxima da fronteira tecnológica".

O resgate crítico da teoria da dependência é fundamental para o entendimento da inserção subordinada que as economias dependentes, e em específico as latino-americanas, apresentam na atual fase do capitalismo contemporâneo. O pensamento dos principais teóricos da dependência mantém-se vivo e articulado frente as vigorosas mudanças que o capitalismo sofreu nos últimos cinquenta anos e, mais particularmente, as contradições e originalidade do capitalismo latino-americano e sua dependência estrutural ao capitalismo das principais nações hegemônicas. Dos Santos, Marini e outros tiveram a tenacidade metodológica de observar que a formação de uma economia capitalista mundial

\footnotetext{
${ }^{20}$ Mercosul é a abreviação de Mercado Comum do Sul, um bloco econômico sul-americano formado oficialmente pelo Brasil, Argentina, Uruguai, Paraguai e Venezuela. O Mercosul foi criado a partir do Tratado de Assunção, assinado em 26 de março de 1991 pelos governos do Brasil, Argentina, Paraguai e Uruguai, conferir para uma análise critica do Mercosul: Martins (2011); Dos Santos (2015); Souza (2015).
} 
requer a presença de uma relação hierarquizada e competitiva entre formas nacionais como uma dimensão indispensável da base material da acumulação de capital e ponto de partida para a compreensão dos distintos capitalismos nacionais. Nas considerações finais propomos uma agenda de pesquisa que retome a Teoria da Dependência e desenvolva diversos nexos frágeis.

\section{CONSIDERAÇÕES FINAIS COMO UMA AGENDA DE PESQUISA E INTERVENÇÃO}

A Teoria da Dependência constitui um dos esforços teóricos mais originais produzidos por autores radicais latino-americanos. Movendo-se do abstrato ao concreto os autores não apenas contribuíram para a elaboração das especificidades que constitui o capitalismo "sui-generis" das nações subdesenvolvidas, assim como estabeleceram novas categorias na construção critica marxista, enriquecendo seu universo conceitual necessário a interpretação da acumulação de capital nas periferias e na economia mundial, de outro modo renovando o marxismo. As categorias de superexploração do trabalho, subimperialismo, dinâmica de dependência, as quais se somam o padrão de reprodução do capital, são contribuições decisivas de seu pensamento que abrem um enorme campo de investigação e pesquisa.

Todavia, essas contribuições não devem, como alertava Marini ([1973] 2005), ser tomadas dogmaticamente, mas, sim, submetidas ao crivo da revisão radical dos processos históricos, buscando compreendê-los e transformá-los. A TDM no atual esforço de renovação e aprofundamento teórico, tem se colocado vários desafios, algo que pode ser visto como parte da retomada do pensamento critico latinoamericano nesta segunda década do século XXI, entre estes vale destacar:

i) Compreender a estrutura e a dinâmica dos processos de globalização que aprofundam a articulação das principais formações sociais na organização da economia mundial, bem como a influência recíproca que estabelecem entre si: a saber, o capitalismo central de hegemonia estadunidense, o capitalismo dependente periférico e semiperiférico. A interação e interdependência entre essas formas geopolíticas internacionais somente podem ser tratadas a partir das noções de Economia Mundo Capitalista e de Padrão de Reprodução do Capital (Dos Santos, 1993; Marini, 2012; Osorio, 2012). 
ii) Desenvolver a categoria de Padrão de Reprodução do Capital (PRC) enquanto uma forma mediadora entre os níveis mais gerais de análise (modo de produção capitalista e sistema mundial) e os níveis mais histórico-concretos (formação econômico-social nacional e conjuntura). Segundo Osorio (2012, p. 40) o PRC "surge para dar conta das formas como o capital se reproduz em períodos históricos específicos e em espaços geoterritoriais" do capitalismo mundial, "tanto no centro como na semiperiferia e na periferia". O PRC considera a totalidade dos movimentos cíclicos do capital (Capital-dinheiro, Capital-produtivo e Capitalmercadoria), havendo plena interação e interdependência entre os circuitos do capital.

iii) Analisar as mudanças dos regimes políticos e das relações entre as formas de Estados nacionais e classes sociais na América Latina, considerando as instabilidades democráticas e o avanço do neoliberalismo como forma econômica predominante nestas duas primeiras décadas do século XXI.

iv) A vinculação desta região com a dinâmica de crescimento chinesa e suas perspectivas de curto, médio e longo prazo, bem como os riscos de desindustrialização e reprimarização da pauta exportadora da América Latina.

v) O surgimento e crise de governos ou regimes políticos de caráter popular e democrático. Como estes governos suscitaram momentâneos bloqueios parciais a agenda neoliberal e, do mesmo modo, se impuseram crises de soberania à quase totalidade dos países latino-americanos no período recente. Deve-se, ainda, ponderar sobre o novo avanço de regimes autoritários e até mesmo fascistas na região.

vi) Por fim, analisar as perspectivas civilizatórias suscitadas pelo avanço da Economia mundial no século XXI: particularmente, as do socialismo e de civilização planetária multipolar frente à civilização capitalista e sua reprodução hierarquizada do poder e da riqueza.

A agenda de pesquisa que se coloca a nova geração da TDM está diretamente relacionada aos impasses em que a América Latina se encontra neste primeiro quartel do século. Como pondera Martins (2011, p. 352) a busca da "autodeterminação e desenvolvimento" somente se realizará "conciliando as realidades nacional e regional com a mundial". De outro modo: mais do que antes se coloca a imperativa necessidade de reconstrução de um pensamento autônomo latino-americano sobre a dinâmica internacional do capital, não para pensar formas 
isolacionistas, mas para integrar a região na necessária dinâmica de superação do capitalismo.

\section{REFERENCIAS BIBLIOGRÁFICAS}

ALMEIDA FILHO, Niemeyer. O debate atual sobre a dependência. Revista da Sociedade Brasileira de Economia Política, Rio de Janeiro, 2005, v. 16, p. 32-50.

(org.). Desenvolvimento e dependência: cátedra Ruy Mauro Marini. Brasília: IPEA, 2013, 233p.

\section{AMARAL, M. S. A Investida Neoliberal na América Latina e as Novas}

Determinações da Dependência. 2006. Dissertação (Mestrado em Economia) Instituto de Economia, Universidade Federal de Uberlândia, Uberlândia. 2006.

AMARAL, Marisa Silva. Teorias do imperialismo e da dependência: a atualização necessária ante a financeirização do capitalismo. Tese de Doutorado- USP, São Paulo, 2012, $147 \mathrm{p}$.

AMARAL, Marisa Silva, Neoliberalismo na América Latina e a Nova Fase da Dependência. Campinas, Brasil, 2007.

ARRIGHI, G. O longo século XX: dinheiro, poder e as origens do nosso tempo. Rio de Janeiro: Contraponto; São Paulo: Editora UNESP, 1996.

Adam Smith em Pequim: origens e fundamentos do século XXI.

São Paulo: Boitempo, 2008.

ASTARITA, Rolando. Economía política de la dependencia y el subdesarrollo. Bernal: UNQ, 2013.

BRESSER-PEREIRA, Luiz Carlos. De la CEPAL y el ISEB a la Teoría de la Dependencia. Desarrollo Económico, vol. 46, № 183, 2006.

BICHIR, Maíra Machado. O subdesenvolvimento econômico da América Latina Sob a perspectiva da Teoria da Dependência. Projeto de pesquisa Fundação de Amparo à Pesquisa do Estado de São Paulo (FAPESP), 2007.

BIELSCHOWSKY, Ricardo. Pensamento Econômico Brasileiro: o ciclo ideológico do desenvolvimentismo. 5ª . ed. Rio de Janeiro: Contraponto, 2000. $496 \mathrm{p}$.

BLOMSTROM, M.; HETTNE, B. La teoria del desarrollo em transicion. México Cit: Fondo de Cultura Económica, 1990. 
CARDOSO, F. H; FALETTO, E. Dependência e desenvolvimento na América Latina: ensaio de interpretação sociológica. Rio de Janeiro: Editora Guanabara, 1970.

CARDOSO, F. H. 1976. "Notas sobre o Estado atual dos estudos de dependência", in: SERRA, J. (Org) América Latina. Ensaios de interpretação econômica. Rio de Janeiro: Paz e Terra, 1976.

CARDOSO, F.H. As idéias e seu lugar: ensaio sobre as teorias do desenvolvimento. Petrópolis (RJ): Vozes, 1993.

CARCANHOLO, M. D. Abertura Externa e Liberalização Financeira: Impactos sobre crescimento e distribuição no Brasil dos anos 90. Tese (Doutorado em Economia) - Instituto de Economia, Universidade Federal do Rio de Janeiro, Rio de Janeiro. 2002.

Abertura e Vulnerabilidade Externa: Restrições Estruturais para o Desenvolvimento em uma Economia Periférica. In: XAVIER, C.L. Desenvolvimento Desigual. Uberlândia: Edufu, 2004. cap. 2, p.73 - 110.

. Dialética do Desenvolvimento Periférico: Dependência,

Superexploração da Força de Trabalho e Alternativas de Desenvolvimento. In: Anais do IV Colóquio Latino-americano de Economistas Políticos. São Paulo, 31 de outubro a 2 de novembro de 2004.

. Dialética do Desenvolvimento Periférico: Dependência, Superexploração da Força de Trabalho e política econômica. Revista de Economia Contemporânea, Rio de Janeiro, vol. 12, n. 2, p. 247-272, maio/ago. 2008.

DOS SANTOS, Theotônio. The structure of dependence. American Economic Review, vol. 60(2), 1970, p. 231-236.

D.F., 1978. Imperialismo y dependencia, Ediciones Era, México Economia mundial, integração regional e desenvolvimento sustentável: as novas tendências da economia mundial e a integração latino-americana. Petrópolis (RJ): Editora Vozes, 1993.

. O desenvolvimento latino-americano: passado, presente e futuro - uma homenagem à André Gunder Frank. In: CHEW, Sing; DENEMARK, Robert (Orgs.). The underdevelopment of development: essays in honour of André Gunder Frank. Thousand Oaks: Sage Publications, 1996.

Florianópolis: Editora Insular, 2015.

A teoria da dependência: balanço e perspectivas.

DOWBOR, Ladislau. A Formação do Capitalismo Dependente no Brasil. São Paulo: Brasiliense, 1982. 
DUARTE, P. H e GRACIOLLI, E. J. A Teoria da Dependência: Interpretações sobre o (Sub) Desenvolvimento na América Latina. In: V Colóquio Internacional Marx e Engels, Campinas, UNICAMP, 2007.

FRANCO, G. O desafio brasileiro: ensaios sobre desenvolvimento, globalização e moeda. São Paulo: Editora 4, 1999.

FRANK, Andrew Gunder. Desenvolvimento e Subdesenvolvimento Latinoamericano. In PEREIRA, Luiz (org.). Urbanização e Subdesenvolvimento. RJ Zahar, 1973.

GILPIN, Robert. A Economia Politica das Relações internacionais. Brasília: Editora da UNB, 2002.

GOLDENSTEIN, L. Repensando a dependência. Rio de Janeiro (RJ): Paz e Terra, 1994.

GONÇALVES, Reinaldo. Economia Política Internacional: Fundamentos

Teóricos e as Relações Internacionais do Brasil. Rio de Janeiro: Elsevier, 2005.

HUNT, D. Análise da Dependência no Início do Século XXI. In Economia Ensaios, vol. 17/18 (2/1), julho e dezembro, p. 7-18, 2003.

IPEA. Mudanças estruturais na economia global: produção e comércio. In: IPEA. Inserção internacional brasileira: temas de economia internacional (Livro 3, Volume 2). Brasília: Ipea, 2010 (a), p. 133-164.

. A inserção do Brasil em um mundo fragmentado: uma análise do comércio exterior brasileiro. In: IPEA. Inserção internacional brasileira: temas de economia internacional (Livro 3, Volume 2). Brasília: Ipea, 2010 (b), p. 369-393.

JAYME, F.G.; RESENDE, M. F. C. Crescimento econômico e restrição externa: teoria e a experiência brasileira. In: MICHEL, R.; CARVALHO, L. (Org.).

Crescimento Econômico: Setor Externo e Inflação. Rio de Janeiro: Ipea, 2009.

KATZ, Frederico Jayme. Questionando as teorias da dependência e da financeirização: o Brasil na encruzilhada do desenvolvimento do capitalismo. São Paulo: Plêiade, 2011. 288 p.

KAY, Cristóbal. Latin American Theorires os Development and Underdevelopmente. New York: Routledge, 1989.

MANTEGA, Guido. Teoria da dependência revisitada: um balanço crítico. São Paulo: FVG-EAESP, 84 p., Relatório de Pesquisa, 1997.

MARINI, Ruy Mauro. Dialética da Dependência (A). In: SADER, E. Dialética da Dependência. 1a edição. Petrópolis: Vozes, 2000. cap. 2, p.105 - 165. 
"Sobre a dialética da dependência". In: TRASPADINI, Roberta;

STEDILE, João Pedro. Ruy Mauro Marini: Vida e Obra. São Paulo: Expressão Popular, 2005. . Memória. In: TRANSPADINI, R. \& STEDILE, J. P.(orgs.). Ruy Mauro Marini: Vida e obra. São Paulo: Expressão Popular, 2005.

América Latina, dependencia y globalización. Bogotá:

CLACSO y Siglo del Hombre Editores, 2008. Disponível em: <http://biblioteca.clacso.edu.ar/clacso/se/20100830090624/marini.pdf >

. O ciclo do capital na economia dependente. In: FERREIRA, C.; OSORIO, J.; LUCE, M. (orgs.). Padrão de reprodução do capital: contribuições da teoria marxista da dependência. São Paulo (SP), Boitempo: 2012. . Globalização, Dependência e Neoliberalismo na América Latina. Boitempo Editorial, 1ª Edição - 2011, 368 p.

MARTINS, Carlos Eduardo. Superexploração do Trabalho e Acumulação de Capital: reflexões teórico-metodológicas para uma economia política da dependência.

Revista da Sociedade Brasileira de Economia Política, Rio de Janeiro, n. 5, p. 121-138, dez., 1999. Disponível em:

<<http://www.sep.org.br/revista/download?id=65>>

MELLO, João Manuel Cardoso de. O Capitalismo Tardio. São Paulo: Brasiliense, 1994.

MOLLO, Maria de Lourdes Rollemberg. Amado, Adriana Moreira. Desenvolvimento hacia fuera e desenvolvimento hacia adentro erros e acertos da politica economica brasileira. In: Macroeconomia do Desenvolvimento: Ensaios sobre restrição externa, financiamento e política macroeconômica. Editora: Editora da UFPE, 2012, $480 \mathrm{p}$.

NETTO, José Paulo. Nota sobre o marxismo na América Latina. Novos Temas, Salvador/São Paulo, n.5/6, 2012, p.43-60.

OLIVEIRA, Francisco de. Elegia para uma re(li)gião: Sudene, Nordeste, planejamento e conflitos de classes. 2. ed. Rio de Janeiro: Paz e Terra, 1977.

OSORIO, J. Padrão de reprodução do capital: uma proposta teórica. In: FERREIRA, C.; OSORIO, J.; LUCE, M. (orgs.). Padrão de reprodução do capital: contribuições da teoria marxista da dependência. São Paulo (SP), Boitempo: 2012.

OSORIO, J. O Estado no Centro da Mundialização: a sociedade civil e o tema do poder. São Paulo: Outras Expressões, 2014.

PRADO, Fernando Correa. Vânia Bambirra e o marxismo crítico latino-americano. REBELA, v. 1, n. 1, jun. 2011. 
SOUZA, N. A. de. América Latina: inserção internacional, integração e desenvolvimento. In: CRUZ, C. A. S.; CORAZZA, G.; SOUZA, N. A. de (orgs.). América Latina: olhares e perspectivas: Florianópolis (SC): Insular, 2015.

TAVARES. Maria da Conceição. Da Substituição de importações ao capitalismo financeiro. Rio de Janeiro: Zahar Editores, 1983.

TAVARES, M.C. \& G. GOMES (1998). "La Cepal y la Integración de América Latina". In: Revista de la Cepal, número extraordinário, Santiago, outubro de 1998.

TRASPADINI, R.; STEDILE, J.P. Ruy Mauro Marini. Vida e Obra. 1 edição. São Paulo: Expressão Popular, 2005.

TRINDADE, J. R, OLIVEIRA, W. Especialização produtiva primária e meio ambiente em período recente na Amazônia. Novos Cadernos NAEA: v. 14, n. 2, p. 283-302, dez. 2011, ISSN 1516-6481.

VIEIRA, P. A. O Nacionalismo Metodológico no pensamento social latino-americano e a Análise dos Sistemas-Mundo como possibilidade de sua superação. In: XVIII Encontro Nacional de Economia Política, 2013, Belo Horizonte. XVIII Encontro Nacional de Economia Política, 2013.

VIEIRA, P. A. Uma crítica ao conceito de dependência a partir do conceito de economia-mundo. Cadernos de Economia (UNOESC), Chapecó, Ano 8. v. 15, 2004.

WALLERSTEIN, I. EI moderno Sistema Mundial. - vol I e II. Madrid: Siglo Veintiuno, 1987.

Dedico este breve texto ao professor Theotônio dos Santos, mestre e pensador do Brasil e do Mundo. 